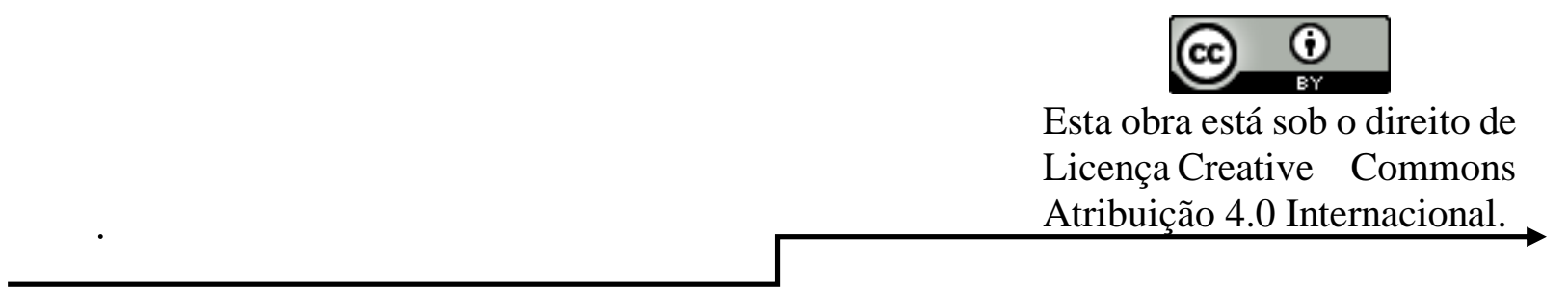

\title{
TECNOLOGIA E LETRAMENTO, AS PREMISSAS PARA O ENSINO APRENDIZADO CONTEMPORÂNEO
}

\author{
Maria das Graças da Silva ${ }^{1}$ \\ Betijane Soares de Barros ${ }^{2}$ \\ Adriano Oliveira Trajano Gomes ${ }^{3}$
}

\section{RESUMO}

É evidente assim como demais campos e setores sociais a educação tende a sofrer ao longo do tempo inovações e transformações, diante de sua realidade desde os preceitos metodológicos, estratégias de ensino, objetivos centrais, formas de avaliação e até mesmo análise acerca das ideias que movimentam a sociedade, logo para que venha seguir os passos mediados pela sociedade a mesma deve trazer fragmentos da mesma para sua realidade, em outras palavras o professor deve diferenciar suas aulas e deixa-las cada vez mais atraentes ao olhar dos alunos, dentre os preceitos principais pode-se citar o usufruo tecnológico atrelado ao letramento para que venha fazer com que o aluno ao mesmo tempo que aprenda premissas sociais e culturais também passe a ter uma certa relação com os aparatos variados tecnológicos.

Palavras-chave: Estratégias. Preceitos. Realidade. Tecnológicos

\begin{abstract}
It is evident, as well as other fields and social sectors, that education tends to undergo innovations and transformations over time, given its reality from the methodological precepts, teaching strategies, central objectives, forms of evaluation and even analysis about the ideas that move society, so that in order to follow the steps mediated by society, it must bring fragments of it to its reality, in other words, the teacher must differentiate his classes and make them increasingly attractive to the students, among the main precepts one can mention the technological enjoyment linked to literacy so that it will make the student, at the same time that he learns social and cultural premises, also start to have a certain relationship with the various technological devices.
\end{abstract}

Keywords: Strategies. Precepts. Reality. Technological

\footnotetext{
1 marciamg@live.com

2 bj-sb@hotmail.com

${ }^{3}$ adriano.trajano@cedu.ufal.br
} 


\section{INTRODUÇÃO}

Assim apontado por MEDEIROS (2016), vivendo uma realidade em que dia após dia, crianças e jovens tende a se sentir desmotivados pelas metodologias aplicadas em sala de aula em um cenário que ainda persevera objetivos e estratégias de desenvolvimento limitado a uma conduta tradicional e tecnicista, profissionais preocupados com a concepção de habilidades e competências socioculturais tentam permitir com que os mesmos tenham um conhecimento que rompam ideias retrogradas e que não venha a distorcer o real sentido da visão sobre mundo.

Dessa maneira, em síntese mediada por PRIMMAZ (2015) ressalta que esquematizam propostas diversas no qual leve o aluno a pensar, conduzir seus próprios conhecimentos e ampliar capacidades que não se estreitam ao longo do tempo, fazendo com que reflitam e desenvolvam um pensamento crítico, pragmático, coeso e coerente, mediante uma roupagem inovadora, de fácil assimilação e que siga os mesmos passos da sociedade contemporânea, já que é notório

\section{METODOLOGIA}

Análise mediada um cunho de revisão bibliográfico, traz consigo o levantamento de preceitos que caracteriza um sistema interativo, partindo da limitação que muitas vezes a escola acaba não acompanhando a evolução social pertinente.

Assim, busca-se associar a introdução do letramento e tecnologia já nas turmas de Ensino Infantil para que os alunos possam se sentir motivados com o que é empregado em sala de aula e venham fazer com que o mesmo reflita na sociedade. No qual pautado por BORGES (2015) o mesmo tende a apresentar uma nova roupagem ao ensino e possibilitar uma relação entre teoria e prática.

Nessas condições a análise em questão feita por MOTTA (2016) tende abordar os desafios enfrentados por tal metodologia ao ser empregada atualmente e quais as contribuições que podem ser alcançadas, vantagens que possibilitam o alcance de fatores positivos para formação social, profissional e até mesmo científica dos alunos, rompendo péssimos hábitos ainda existente na educação brasileira e favorecendo um olhar moderno e transformador, mediante a visão de autores renomados no campo e teorias aclamadas que perpetuam gerações.

da temática, assim como a seleção de perguntas descritivas sobre o norteio da própria estratégia em busca de descritores e bases que formatam dados mais que eficazes nas publicações dos últimos anos, 
tendo como critérios a exclusão e inclusão das mesmas.

Os estudos por sua vez têm uma premissa que são identificados através da seleção detalhada por meio da leitura de agentes indexadores de publicações amplas, mediante a resumos, assim como também palavras-chave e demais títulos vigentes, da mesma forma que a organização dos estudos pré-selecionados e elaboração e uso de síntese.
É apontado além dos pontos que são tidos como essenciais para a realização da pesquisa, a integração de informações múltiplas decorrente a formação de uma biblioteca individual e a própria avaliação crítica dos estudos rigorosamente detalhados e selecionados, como uma forma interpretativa e discursiva dos resultados e a apresentação da revisão em formato de artigo, com intuito de compor as premissas estabelecidas para estudos prósperos.

Quadro 01 - Detalhamento das etapas da Revisão Integrativa.

\begin{tabular}{|c|c|c|c|c|}
\hline ETAPA & $\begin{array}{l}\text { TÓPICOS DE CADA } \\
\text { ETAPA }\end{array}$ & \multicolumn{3}{|c|}{ DETALHAMENTO DE CADA TÓPICO } \\
\hline & Tema & \multicolumn{3}{|c|}{$\begin{array}{c}\text { TECNOLOGIA E LETRAMENTO, AS PREMISSAS } \\
\text { PARA O ENSINO APRENDIZADO } \\
\text { CONTEMPORÂNEO }\end{array}$} \\
\hline & Pergunta norteadora & \multicolumn{3}{|c|}{$\begin{array}{l}\text { Quais as premissas que devem-se buscar para que venha } \\
\text { ter a associação entre tecnologia e letramento? }\end{array}$} \\
\hline & Objetivo geral & \multicolumn{3}{|c|}{$\begin{array}{l}\text { Apresentar preceitos sociais atuais que podem ser } \\
\text { alcançados com o letramento e a contribuição que a } \\
\text { tecnologia pode vir oferecer para tal alcance. }\end{array}$} \\
\hline & & \multicolumn{3}{|c|}{$\begin{array}{l}\text { Cruzamento de descritores por meio do operador } \\
\text { booleano AND; }\end{array}$} \\
\hline & Estratégias de busca & \multicolumn{3}{|c|}{$\begin{array}{l}\text { Uso de descritores estruturados (codificação) no } \\
\text { DECS ou MESH; }\end{array}$} \\
\hline & & \multicolumn{3}{|c|}{ Uso de metadados (filtros). } \\
\hline $1^{a}$ & \multirow{3}{*}{ Bancos de terminologias } & Banco & \multicolumn{2}{|c|}{ Link } \\
\hline & & DeSC & \multicolumn{2}{|c|}{ http://decs.bvs.br/ } \\
\hline & & $\mathrm{MeSH}$ & \multicolumn{2}{|c|}{ https://www.ncbi.nlm.nih.gov/mesh } \\
\hline & \multirow[t]{3}{*}{$\begin{array}{l}\text { Descritores livres e } \\
\text { estruturados }\end{array}$} & Descritor & DeSC (Registro) & $\begin{array}{l}\text { MeSH } \\
\text { (Identificador } \\
\text { Único) }\end{array}$ \\
\hline & & Letramento & 6785 & D005783 \\
\hline & & Tecnológia & 13704 & $\mathrm{D} 011057$ \\
\hline & String de busca & \multicolumn{3}{|c|}{ Literacy AND Technology AND Literacy } \\
\hline & \multirow{4}{*}{ Bibliotecas Virtuais } & \multicolumn{3}{|c|}{ Link } \\
\hline & & BVS & \multicolumn{2}{|c|}{ https://bvsalud.org/ } \\
\hline & & Scielo & \multicolumn{2}{|c|}{ https://search.scielo.org/ } \\
\hline & & PubMed & \multicolumn{2}{|c|}{ https://www.ncbi.nlm.nih.gov/pubmed/ } \\
\hline
\end{tabular}




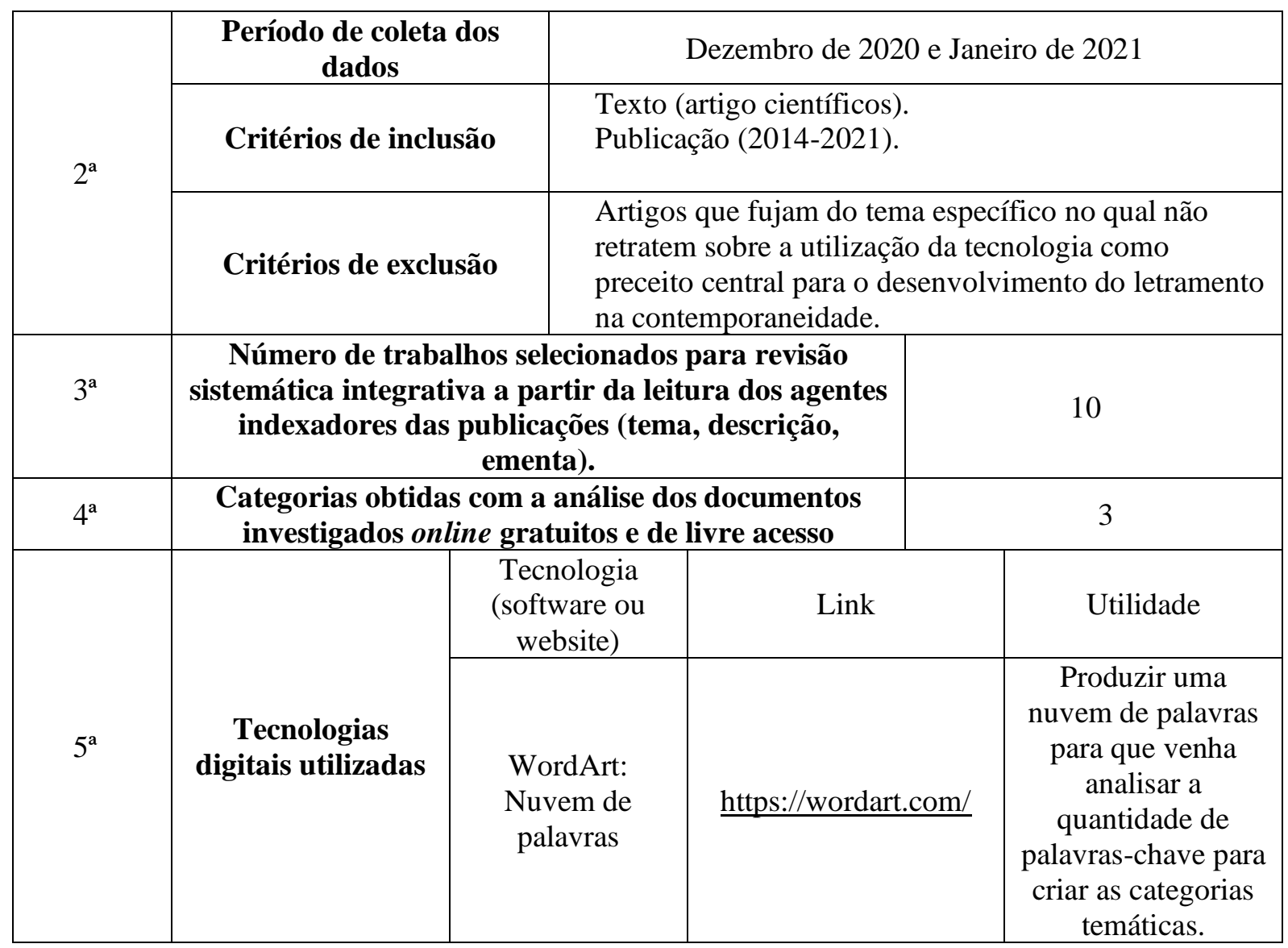

Fonte: Elaborada pela autora

\section{RESULTADOS}

Quadro 2 - Corresponde ao total de documentos disponíveis nas Plataforma BVS, Scielo, PubMed obtidos por string de busca.

\begin{tabular}{|c|c|c|c|c|}
\hline \multirow{2}{*}{ String de busca } & $\begin{array}{c}\text { Bases de } \\
\text { dados } \\
\text { Plataforma }\end{array}$ & $\begin{array}{c}\text { Total de } \\
\text { publicações sem } \\
\text { o filtro }\end{array}$ & $\begin{array}{c}\text { Publicações } \\
\text { disponíveis após } \\
\text { aplicar os filtros }\end{array}$ & $\begin{array}{c}\text { Publicações } \\
\text { aproveitadas na } \\
\text { Revisão Sistemática } \\
\text { Integrativa }\end{array}$ \\
\hline $\begin{array}{c}\text { Letramento AND } \\
\text { Tecnologia AND } \\
\text { Alfabetização } \\
\text { Literacy AND } \\
\text { Technology AND } \\
\text { Literacy }\end{array}$ & BVS & 180 & 30 & 5 \\
\cline { 2 - 5 } & Scielo & 5 & 3 & 3 \\
\hline
\end{tabular}

Fonte: Autoria própria.

No total detectou-se um total de 190 publicações que traziam consigo a temática central da pesquisa, logo de todas as publicações científicas pode ser notado que 30 eram considerados artigos disponíveis após o uso dos filtros, no qual foram 
realizados um total de 10 downloads, que inclusão, submetidos as etapas da revisão obedeceram a premissa dos critérios de integrativa.

Quadro 03 - Descrição dos documentos (artigos) de acordo com os critérios de tecnologia e letramento.

\begin{tabular}{|c|c|c|c|c|}
\hline $\mathbf{N}^{\mathbf{o}}$ & Autor(a) & Tema & Ano & Conclusão \\
\hline 1 & $\begin{array}{l}\text { Raquel Aparecida } \\
\text { Soares Reis Franco } \\
\text { Maria Lúcia } \\
\text { Castanheira }\end{array}$ & $\begin{array}{c}\text { Práticas de Letramento } \\
\text { Acadêmico no } \\
\text { Facebook }\end{array}$ & 2016 & $\begin{array}{l}\text { O presente artigo faz uma reflexão voltada } \\
\text { as condutas práticas de letramento } \\
\text { acadêmico e digital ampliadas e } \\
\text { desenvolvidas durante o processo do curso } \\
\text { de especialização de Linguagem e } \\
\text { Tecnologia, no qual são produzidas por os } \\
\text { alunos pesquisadores decorrentes o curso } \\
\text { de especialização que traz consigo a } \\
\text { conduta do Facebook como Ambiente } \\
\text { Virtual de Aprendizagem, favorecendo no } \\
\text { ensino de gêneros textuais, conhecimentos } \\
\text { ortográficos e até mesmo engajamento de } \\
\text { temáticas sociais atuais. }\end{array}$ \\
\hline 2 & Edgar Roberto Kirchof & $\begin{array}{l}\text { Como ler os textos } \\
\text { literários na era da } \\
\text { cultura digital? }\end{array}$ & 2016 & $\begin{array}{l}\text { É apresentado no mesmo no panorama das } \\
\text { mais vastas transformações no campo } \\
\text { literário, em que afirma o surgimento da } \\
\text { tecnologia digital que referência as } \\
\text { discussões e a própria teorização diante a } \\
\text { leitura de obras literárias no contexto, } \\
\text { desenvolvidos por meio de transformações } \\
\text { expondo liberdade para produzir e até } \\
\text { mesmo publicar tanto o texto quando blogs } \\
\text { e sites, apresentando concepções sobre } \\
\text { leitura literária no universo digital, } \\
\text { também ressaltando o perigo do } \\
\text { determinismo tecnológico para com as } \\
\text { discussões polarizadas das leituras no } \\
\text { universo digital. }\end{array}$ \\
\hline 3 & Zulmira Medeiros & $\begin{array}{c}\text { Gêneros, } \\
\text { multimodalidade e } \\
\text { letramentos }\end{array}$ & 2014 & $\begin{array}{l}\text { A mesma traz consigo a análise de caráter } \\
\text { multimodalidade diante do cenário virtual, } \\
\text { que tem como premissa principal a } \\
\text { apropriação de gêneros discursivos e } \\
\text { letramento acadêmico vividos por alunos, } \\
\text { fazendo com que chegue a compreensão } \\
\text { das relações dos sujeitos e construção entre } \\
\text { si e com o próprio ambiente multimodal } \\
\text { por meio de uma escrita online, afirmando } \\
\text { a influência da mesma nas escolhas, } \\
\text { contribuição para escrita e relações } \\
\text { estabelecidas entre si, com a própria } \\
\text { tecnologia e com o meio acadêmico. }\end{array}$ \\
\hline 4 & Karin Quast & $\begin{array}{l}\text { Gamificação, ensino de } \\
\text { línguas estrangeiras e } \\
\text { formação de } \\
\text { professores }\end{array}$ & 2020 & $\begin{array}{l}\text { O mesmo traz consigo reflexões acerca dos } \\
\text { benefícios trazidos desde o Ensino Infantil } \\
\text { até mesmo o Ensino Médio, as } \\
\text { contribuições que os jogos digitais e } \\
\text { virtuais têm haver com o desenvolvimento } \\
\text { de competências aos alunos, em especial } \\
\text { nas disciplinas direcionadas a Línguas, } \\
\text { tanto a nacional, como também a } \\
\text { estrangeira, baseando em uma visão } \\
\text { comportamentalista, skinneriana, }\end{array}$ \\
\hline
\end{tabular}




\begin{tabular}{|c|c|c|c|c|}
\hline & & & & $\begin{array}{l}\text { defendendo antes de tudo o papel dos } \\
\text { educadores assim como o favorecimento } \\
\text { no contexto de letramento e alfabetização. }\end{array}$ \\
\hline 5 & $\begin{array}{l}\text { Maria del Carmen de la } \\
\text { Torre Aranda } \\
\text { Maximina Maria Freire }\end{array}$ & $\begin{array}{l}\text { Narrativas transmídia: } \\
\text { entre multiletramentos } \\
\text { e letramentos } \\
\text { transmídia }\end{array}$ & 2020 & $\begin{array}{l}\text { O objetivo central do artigo é apresentar } \\
\text { sobre as análises das narrativas transmídias } \\
\text { e investigativas, no qual enfoca na amostra } \\
\text { da adequação da produção vasta de } \\
\text { condutas situacionais e culturais } \\
\text { convergentes, trazendo a tona a reflexão de } \\
\text { questões de letramento e o pluralismo } \\
\text { pedagógico, destacando perspectivas } \\
\text { multiletramentos e noções das } \\
\text { perspectivas do pluralismo, as abordagens } \\
\text { e extensão da narrativa ao longo dos ciclos, } \\
\text { no próprio artigo é visto a visão de autores } \\
\text { contemporâneos em elo com a reflexões de } \\
\text { pensadores renomados no qual a uma } \\
\text { investigação se tal premissa tende a } \\
\text { garantir a evolução do aprendizado do } \\
\text { aluno e quais pontos dentro de sala de aula } \\
\text { tem que ser mudados para ampliar os } \\
\text { benefícios. }\end{array}$ \\
\hline 6 & $\begin{array}{l}\text { Rebecca Ortiz La } \\
\text { Banca } \\
\text { Lucila Castanheira } \\
\text { Nascimento }\end{array}$ & $\begin{array}{c}\text { Posicionando a criança } \\
\text { no centro do seu } \\
\text { cuidado: reflexões } \\
\text { sobre o } \\
\text { desenvolvimento } \\
\text { cognitivo e o } \\
\text { letramento em saúde } \\
\text { infantil }\end{array}$ & 2019 & $\begin{array}{l}\text { O presente artigo apresenta as reflexões } \\
\text { advindas ao desenvolvimento cognitivo e } \\
\text { letramento em saúde infantil, a partir da } \\
\text { década de } 60 \text {, o processo de introdução das } \\
\text { necessidades da população pediátrica, } \\
\text { elencadas sob a perspectiva da própria } \\
\text { clientela, tendo como cenário principal a } \\
\text { era digital de comunicação, fundamental } \\
\text { afim de reconhecer os mesmos com } \\
\text { ligação aos preceitos pedagógicos, } \\
\text { interdisciplinares e plurais. Tendo o } \\
\text { letramento ao processo dinâmico e } \\
\text { influenciado por fatores pessoais, } \\
\text { situacionais, societários e até mesmo } \\
\text { ambientais, sendo explicada por meio de } \\
\text { três categorias centrais, cognitiva, } \\
\text { comportamental/operacional } \\
\text { afetiva/conativa. }\end{array}$ \\
\hline 7 & Gisela Wajskop & $\begin{array}{l}\text { Linguagem Oral e } \\
\text { Brincadeira Letrada } \\
\text { nas Creches }\end{array}$ & 2017 & $\begin{array}{l}\text { O artigo visa contribuir a reflexão diante as } \\
\text { relações as brincadeiras e aprendizagens } \\
\text { diante da linguagem oral em contextos } \\
\text { narrativos significativos em creches, } \\
\text { apresentando, resultados de pesquisa-ação } \\
\text { em curso, mediante uma narrativa } \\
\text { emergente construído por meio crianças, } \\
\text { resultados revelam a integração entre } \\
\text { brincar e aprender, mediados a literatura } \\
\text { infantil fornecendo ao repertório } \\
\text { linguístico e semântico significativo ás } \\
\text { produções expressivas e comunicativas } \\
\text { entre as criancas. }\end{array}$ \\
\hline 8 & Rildo Cosson & $\begin{array}{l}\text { Literatura infantil em } \\
\text { uma sociedade pós- } \\
\text { literária: a dupla } \\
\text { morfologia de um } \\
\text { sistema cultural em } \\
\text { movimento }\end{array}$ & 2016 & $\begin{array}{l}\text { Faz reflexões mediante a sociedade as } \\
\text { profundas das transformações } \\
\text { tecnológicas e culturais, que trazem } \\
\text { consigo o estudo de modificações e } \\
\text { relações entre as artes, relações entre } \\
\text { indivíduos diante do mundo simbólico, } \\
\text { ressaltando a forma com que o leitor se }\end{array}$ \\
\hline
\end{tabular}




\begin{tabular}{|c|c|c|c|c|}
\hline & & & & $\begin{array}{l}\text { comporta atualmente, a razão para } \\
\text { continuar a ensinar literatura, partindo de } \\
\text { pressupostos teóricos da educação } \\
\text { comparada, diante da teoria dos } \\
\text { polissistemas e do letramento literário, } \\
\text { encontrando os caminhos de respostas e } \\
\text { analise de configurações paradigmáticas } \\
\text { da literatura infantil. }\end{array}$ \\
\hline 9 & $\begin{array}{l}\text { Tatiane Henrique } \\
\text { Sousa Machado } \\
\text { Cristiane Carneiro } \\
\text { Capristano }\end{array}$ & $\begin{array}{c}\text { Rasuras ligadas á } \\
\text { segmentação de } \\
\text { palavras na aquisição } \\
\text { da escrita }\end{array}$ & 2016 & $\begin{array}{l}\text { Traz consigo reflexões diante dos } \\
\text { pressupostos que mediam rasuras as } \\
\text { ligadas segmentações de palavras, que } \\
\text { evidenciam a constituir indícios aos mais } \\
\text { importantes conflitos vivenviados as } \\
\text { crianças, inteirada a ortografia, } \\
\text { apresentando e até mesmo descrevendo } \\
\text { aos possíveis fatores que concorrem as } \\
\text { emergentes rasuras, constatado a } \\
\text { influência do capital ao letramento e } \\
\text { instauração de conflitos sobre segmentos, } \\
\text { patente de modo a circulação das crianças } \\
\text { práticas sociais orais, entrelaçada a } \\
\text { circulação das crianças por práticas } \\
\text { letradas. }\end{array}$ \\
\hline 10 & $\begin{array}{c}\text { Vanessa Ferraz } \\
\text { Almeida Neves } \\
\text { Maria Lúcia } \\
\text { Castanheira } \\
\text { Maria Cristina Soares } \\
\text { Gouvêa }\end{array}$ & $\begin{array}{c}\text { O letramento e o } \\
\text { brincar em processos } \\
\text { de socialização na } \\
\text { educação infantil } \\
\text { brincadeiras diferentes }\end{array}$ & 2015 & $\begin{array}{l}\text { Apresenta como objetivo central a } \\
\text { investigação geral a análise do cotidiano } \\
\text { de uma escola pública de educação infantil } \\
\text { da cidade de Belo Horizonte em Minas } \\
\text { Gerais, no incentivo para com a leitura e } \\
\text { escrita, mediante as brincadeiras diversas, } \\
\text { no qual esses estudos situa-se no contexto } \\
\text { das discussões sobre o letramento e da } \\
\text { alfabetização na Educação Infantil, } \\
\text { fazendo parte do estudo mais abrangente, } \\
\text { ao desenvolvimento por base da } \\
\text { abordagem etnográfica interacional, } \\
\text { interpretativa da sociologia da infância e } \\
\text { perspectiva social do letramento. }\end{array}$ \\
\hline
\end{tabular}

\section{O corpo textual é composto pela} analise brando do meio da frequência de palavras, que possibilitou para originar a nuvem de palavras (Figura 1) surgida na
Plataforma online WordArt. No qual a mesma é formatada pelo agrupamento e organização gráfica de palavras-chave evidenciando sua frequência. 
Figura 1. Nuvem de palavras.

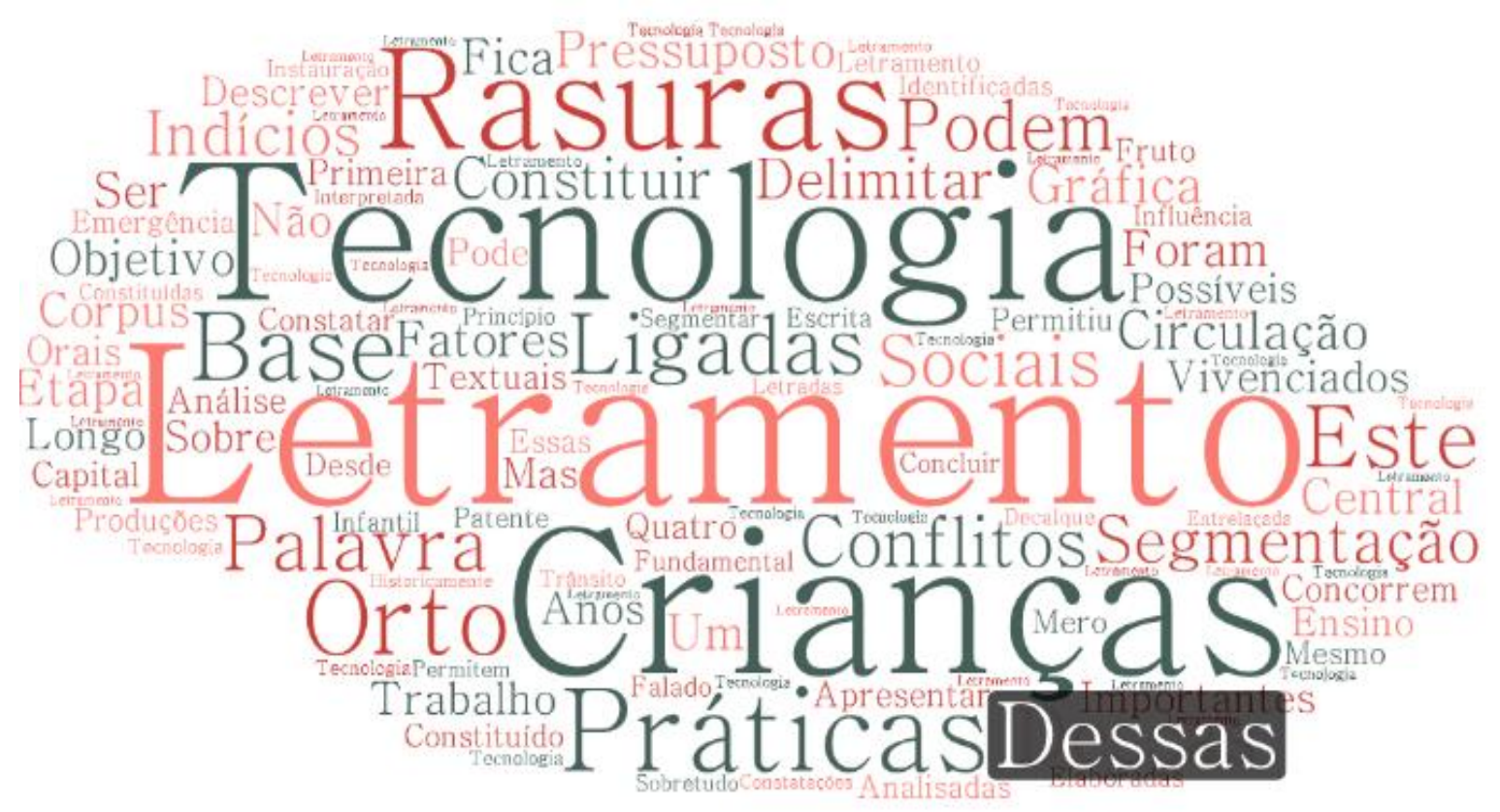

Fonte: Autoria própria.

Mediante o que está sendo exposto na Figura 1, pode perceber que as palavras existentes, há um grande destaque para as "letramento" e "tecnologia", no qual pertencem as categorias desenvolvidas na análise do conteúdo, todas as mesmas derivam da frequência já apresentada na Tabela 1, que expõem seu quadro referencial.
Diante do objetivo central exposto no artigo, equivale-se que a descrição do mesmo surge no conjunto de palavras variadas que apresentam a frequência total no texto e, dessa forma os sentidos nos campos textuais, com uma grande relevância em suas representações sociais diante também do exposto no Quadro 2.

Tabela 1. Frequência das palavras presentes nos textos publicados pelos artigos nas Plataformas: BVS, Scielo e PubMed.

\begin{tabular}{|c|c|c|}
\hline PALAVRAS & FREQUÊNCIA & CATEGORIAS \\
\hline Tecnologia & 8 & \begin{tabular}{lcr} 
AS & \multicolumn{2}{r}{ FERRAMENTAS } \\
TECNOLÓGICAS & & COMO \\
AUXILIADORAS & NO & PAPEL \\
DOCENTE & NOS & DIAS \\
CONTEMPORÂNEOS & \\
\end{tabular} \\
\hline Letramento & 4 & $\begin{array}{l}\text { LETRAMENTO E ALFABETIZAÇÃO } \\
\text { COM O APOIO DAS FERRAMENTAS } \\
\text { TECNOLÓGICAS }\end{array}$ \\
\hline
\end{tabular}




\begin{tabular}{l|l|l}
\hline Crianças & 4 & OS DESAFIOS DE EDUCAR \\
& & CRIANÇAS EM UMA SOCIEDADE \\
& EM & TRANSFORMAÇÃO CONSTANTE \\
\hline
\end{tabular}

Fonte: autora

\section{DISCUSSÃO}

O letramento já foi apresentado várias vezes que trouxe grandes vantagens para o meio educacional, logo o mesmo deve ser associado com a realidade da sala de aula, sendo empregado inovações que permeiem capacidades diversas aos alunos e consequentemente uma certa facilidade na interação social e os conteúdos que mediam ao conteúdo passado pelas áreas de conhecimento.

\section{AS}

TECNOLÓGICAS

AUXILIADORAS

DOCENTE CONTEMPORÂNEOS

\section{FERRAMENTAS} COMO PAPEL DIAS

É na escola que o aluno além de assimilar os preceitos básicos de formação científicas, voltadas as ideias de teorias e conhecimentos das múltiplas áreas, são eles também que devem desenvolver competências e habilidades diversas que visem se comprometer com os ideais de democracia, justiça, socialização e interação com o público, pautado principalmente a questões éticas, morais, reflexivas, críticas e antológicas.

No qual conforme o tempo os mesmos devem acompanhar o desenvolvimento social, é visto que novas demandas passam ser exigidas ao longo do tempo, necessitando como apontado por MIYAZAKI (2017, p. 13)," sair do tradicional, do quadro e do giz para o quadro branco em que não há mais giz, para a lousa virtual e para os sistemas interativos de comunicação".

Dessa forma a tecnologia de informação e comunicação acaba invadindo o cenário educacional, e fazendo com que educadores, educandos e todos os demais funcionários tracem novos comportamentos para associar os preceitos que devem ser evidenciados no ensino e siga o compasso apresentado pela sociedade, compondo e formatando um perfil diferenciado e transformador a sociedade de modo geral e de caráter amplo.

Além dessa contribuição a mesma faz com que venha atingir uma conduta no qual favoreça ao mercado de trabalho e a ampliação de vantagens interativas socioculturais, fazendo com que os alunos tenham melhores e maiores experiências e possibilitem uma visão diferenciada da que pode ser vista atualmente direcionada a questões individuais e situações limitadas. PRIMMAZ (2015) aponta que assim favorece na construção de ambientes ricos e auxiliando na alfabetização de crianças, 
havendo uma reflexão por parte dos professores sobre suas possibilidades.

Diante disso passasse a ingressar uma premissa no qual quebra velhos paradigmas e favorece uma conjuntura diferenciada, no qual media-se através da informática, tecnologia de informação e comunicação e na própria educação. MIYAZAKI (2017, p. 16) aponta que "na hora em que se muda um paradigma tem-se que mudar a forma de tratar isso porque a escola faz parte de uma sociedade, a mídia faz parte de uma sociedade. A sociedade é midiatizada, ou seja, pensa de acordo com a lógica de mídia. Logo, a escola também terá de pensar no mesmo sentido a fim de que cumpra o seu papel."

Para muitos a informática é de grande valia para o meio de comunicação, mas ela vai além disso, já confirmou sua permanência e vinculação com o meio empresarial, contábil e público, seguindo a mesma ideia confirma sua participação no meio educacional, no qual possibilita a geração de informações de maneira automática, através de ferramentas diversas como o notebook, desktop, notebook, tabletes e pager em geral, assim como os próprios celulares.

PRIMMAZ (2015) afirma que esses aparelhos por sua vez eram sinônimos de processos ligados a armazenamento e processo de informações, mas atualmente vai além disso, conectado com a internet já tem a capacidade de transmitir informações amplas e favorecer a vida do educando no qual ele para a ter acessos a informações de forma rápida e das mais variadas fontes.

Usado nos mais variados campos da sociedade moderna, o computador pode apresentar aos discentes as vantagens de ter acesso a vídeo, áudio e imagem, o que deixa ainda mais atraente ao seu usuário, fortalecendo laços, interações e concepções diversas. MIYAZAKI (2017) afirma que só cabe ao professor usufruir do mesmo afim de que possa ser associado em suas aulas, no qual o aluno o veja como um complemento não como algo fundamental, a figura do educador é indispensável e sem seu auxilio não poderá ter domínio do que será mediado ou apresentado ao computador.

PRIMMAZ (2015) também afirma que os recursos tecnológicos são essenciais ao contexto educacional, se tornando assim uma essencial ferramenta para que possa favorecer o aprendizado de forma muito mais dinamizado. Não só através do computador, mas a informática e a conexão em redes estão presentes em todos os aspectos da vida social e até mesmo cultural do cidadão, tanto em pontos da área urbana, assim como também na área rural. 
2. LETRAMENTO ALFABETIZAÇÃO COM O APOIO DAS TECNOLÓGICAS

Escolas diversas buscam formas de fazer com que as metodologias empregadas pelos professores na contemporaneidade venham sofrem uma evolução e consequentemente permitir com que os professores alcancem objetivos já estipulados pela sociedade já nos anos finais da década de 90 e início dos anos 2000, no qual é fazer com que o aluno cada vez mais tenha sua vida atrelada ao meio tecnológico.

Diante disso, BORGES (2015) aponta que pode perceber que nas concepções sociais, tal ponto é alcançado, os alunos estão cada vez mais centrados a este campo, seja através da realização de uma simples busca no google, utilização de um aplicativo ou até mesmo o uso incessante do celular para realizar atividades que antigamente necessitada de uma demanda maior, como a realização de pedidos do gênero alimentício, de transporte ou até mesmo formas variadas de estudo.

Com isso a escola carece em seguir esses passos, já que acaba utilizando uma metodologia que fica a desejar, comparado a tudo que os alunos podem encontrar no meio virtual, na própria internet, em sites, canais, blogs ou até mesmo nas redes socais. Já na primeira infância é notório que a criança consegue já executar funções básicas, acessar aplicativos, fazer downloads, trocar informações, antes mesmo de ser alfabetizado.

Assim acoplando essas ferramentas na sala de aula, MOTTA (2016) afirma que os alunos acabam tendo um olhar diferenciado, eles passam enxergar aqui apontado pelo seu professor como algo contínuo e que até mesmo pode ser associado com sua realidade, o aluno tira fragmentos dentro da sala de aula para a sua casa, fazendo com que aproxime ainda mais $\mathrm{o}$ elo entre aquilo passado em classe e presente em suas residências.

Com esse compilado de todas essas vantagens tidas, BORGES (2015) menciona que as instituições de ensino buscam usufruir de todos esses recursos, mas sabese que não é somente a presença de um aparato tecnológico que fará com que por si só atinja tais fatores positivos, ao contrário, é preciso ter dedicação dos professores e saber desenvolver um plano de aula no qual utilize esses recursos e também não esqueça os preceitos que permeiam o ensino aprendizagem.

Dessa forma, MOTTA (2016) ressalta também que cabe o professor buscar maneiras de se especializar, fazendo com que traga consigo a carga experiências e conhecimentos sobre o assunto, para isso cursos diversos são buscados pelos mesmos para que venha conhecer a realidade a cerca 
dessa realidade, possibilitando com que interaja também com participações em workshoppings, formações diversas, eventos e até mesmo em congressos.

Tudo isso pode ser inteirado com iniciativas das instituições de ensino, BORGES (2015) evidencia que "assim como também pode agir por conta própria, fazendo com que os professores venham a concretizar ideias mais inovadoras e as mesmas sejam refletidas na forma de atuação no dia a dia”, na aplicação que segue seu planejamento, na análise diante dos educandos e sendo base até mesmo da avaliação aplicada em classe.

MOTTA (2016) diz que se torna uma grande vantagem principalmente com tais ferramentas são aplicadas já na Educação Infantil é visto que são muitos os alunos que acabam tendo o domínio das ferramentas de tecnologia da informação e comunicação de forma cada vez mais precoce, nesse momento é crucial quando associado a escola, passar conhecimentos dirigidos aos cuidados que precisam se ter, os limites que não podem ultrapassar e também como associa-los com sua vida.

A tecnologia está ligada a muitos pontos que não só vem contribuir para o ensino, mas para o lazer, saúde, o desenvolvimento profissional, a comunicação, mas tudo em excesso acaba possibilitando o desenvolvimento de fatores negativos e os mesmos rompem as vantagens que a mesma conquistou. BORGES (2015) aponta que dentre os mesmos pode-se destacar os problemas físicos voltados a visão, audição e pela própria concentração, assim como também problemas psicológicos, como a falta de socialização, problemas de interação e até mesmo princípios de agressividade, ansiedade e tolerância.

Por isso, se faz necessário com que saiba como trabalhar com a tecnologia em sala de aula, apesar de grandes vantagens que podem ser alcançadas, de que forma ela pode oferecer na maximização das premissas que estabelecem a alfabetização e letramento, como desenvolver estratégias em que os alunos percam muitos vícios tecnológicos desenvolvidos em casa e os convertam benefícios, que ultrapassem as paredes das escolas e se torne uma realidade presente na sociedade contemporânea.

\section{OS DESAFIOS DE EDUCAR EM UMA SOCIEDADE EM CONSTANTE TRANSFORMAÇÃO}

A sociedade está em constante processo de transformação, fator esse que faz com que muitas vezes objetivos e estratégias que busca-se alcançar acaba consequentemente tendo que renovar ao longo do tempo, é evidente que a cada ano novas premissas devem compor aos planejamentos da instituição de ensino, logo, é notado que essa mudanças estão 
ocorrendo de forma cada vez mais rápida, como exemplificação toma-se como exemplo o processo metodológico do ano de 2020, no qual teve que adotar o ensino remoto, por conta da pandemia do novo coronavírus COVID-19.

COSSON (2016) afirma que é visto que a sociedade se transforma em um acelerado processo e se desfaz em uma impressionante rapidez. Nessas condições nos últimos anos pode-se afirmar que a informática se torna uma grande ferramenta, no qual visa possibilitar o aprendizado de modo mais dinamizado. Sem falar que todo acervo tecnológico faz parte da realidade da sociedade, fazendo parte na composição dos preceitos culturais e dinâmicos.

Quando um educador desenvolve uma atividade no qual o aluno tenha que ter o contato com algum material tecnológico, ele está possibilitando ao mesmo que venha assimilar condutas que regem a práticas sociais diversas, enfatizem concepções de linguagem e permita o rompimento de condutas errôneas aplicadas ainda hoje dentro e fora da sala de aula. MEDEIROS (2016) também essa metodologia liberta o aluno a conhecer a realidade dos mais diferentes lugares do mundo, "inclusive até mesmo interagir com pessoas desses mesmo lugares, através de textos, imagens, vídeos ou arquivos de áudio", fazendo com que aprenda um pouco mais sobre as culturas existente em todo mundo.

COSSON (2016) afirma favorecendo assim no diálogo dos alunos e permitindo com que os mesmos possam opinar por mais variadas problemáticas, também com o uso dos recursos dos aparatos tecnológicos os educadores podem oferecem linguagens sociais reais, através dos múltiplos aparelhos tecnológicos, pode ser desenvolvido uma galeria de fotos podendo realizar um comparativo ao longo do tempo, acessar vídeos, imagens, textos que trazem consigo informações pertinentes e até mesmo se comunicar com pessoas de outros países e até mesmo de outros continentes.

O compartilhamento de informações para a sociedade também acontece de forma muito fácil, são diversos os cidadãos que divulgam sua vida nas redes sociais, desta maneira, facilitando o dialogo das pessoas e conduzindo uma visão ainda mais interativa, isso possibilita com que sejam quebrados tabus de socialização fazendo com que seja um vínculo de expressão artística, social e até mesmo cultural.

MEDEIROS (2016) afirma que assim a tecnologia é vista como um dos preceitos base para o desenvolvimento da educação de qualidade, logo a mesma não se restringe única e exclusivamente ao uso de tecnologias, ao contrário, dessa maneira favorece a formação de professores, 
gestores e até mesmo da própria escola, permitindo o desenvolvimento do trabalho colaborativo diante do próprio projeto político pedagógico, como também a participação de uma educação democrática, inclusiva e provedora de um ensino aprendizado ao longo da vida.

COSSON (2016) confirma assim que, portanto, as tecnologias são importantes como apoio, haja vista que a educação de qualidade pode ser feita até sem uso das tecnologias, mas no mundo atual, no mundo já conectado, em rede, ficaria inadequado trabalhar todos esses conteúdos sem essa mediação que usamos no cotidiano, no dia a dia, no trabalho, concomitantemente, urge também a educação para as mídias, para compreendê-

\section{CONCLUSÃO}

Diante do que foi exposto pode confirmar que pautada as indagações feitas acerca de autores diversos contemporâneos, porém influenciados por teorias de pensadores como Freire, Piaget e Ferrero, pode afirmar que a sociedade vive em constante mudança e que cabe o professor se adequar essas transformações fazendo com que ofereça oportunidade aos seus alunos conhecimentos modernos em contraste com concepções e ideias modernas. las, criticá-las e utilizá-las de forma mais abrangente possível.

O processo de mídia é de grande importância para o processo de aprendizado, principalmente para crianças e jovens, no qual nasceram em uma época, no qual os aparatos tecnológicos são utilizados para realizar as mais diversas tarefas do cotidiano. MEDEIROS (2016) confirma assim que nessas condições o professor deve buscar preceitos de afetividade, humanismo e até mesmo ética, no qual o mesmo deve ser criativo, assim como orientador, experimentador e até mesmo processo de aprendizagem, nessas condições trazendo benefícios para o desenvolvimento da alfabetização e do letramento, pela prática de ensino aos alunos para o melhoramento de sua vida.

A tecnologia é vista por muitos ainda como um fator negativo para o desenvolvimento e aprendizado do aluno, fazendo com que assim o professor venha desenvolver técnicas e habilidades em que permita com que aproxime aos mesmos conhecimentos mediados a uma proposta metodologia de uso abrange da tecnologia, é notório que são inúmeros recursos que podem ser utilizados e façam com que contribuam na formação do discente.

Essa formação vai muito mais além do saber científico, no domínio de teorias, teoremas, ideias limitadas ao papel da 
escola, mas também traga vantagens direcionadas ao campo social, cultural e até mesmo profissional, afinal é por meio do que é atribuído na escola que os mesmos passam assumir novas visões de vida, contempladas pelo o papel do letramento.

Apesar de tal proposta ter fragmentos que configurem uma metodologia aplicada a crianças é percebido que a mesma pode ser muito bem empregada para séries que vão desde a Educação Infantil até mesmo ao próprio Ensino Médio, uma vez que a gamificação, ou seja, a utilização de jogos eletrônicos é uma atividade que não se restringe a uma única faixa etária, ao contrário vai além, chegando até muitas plataformas de aprendizado se atualizarem afim de que garanta vantagens a assimilação de múltiplos conteúdos, principalmente aqueles voltados as Ciências Exatas.

\section{REFERÊNCIAS}

ARANDA, Maria del Carmen de la Torre; FREIRE, Maximina Maria. Narrativas transmídia: entre multiletramentos e letramentos transmídia. Trab. linguist. apl. vol.59 no.2 Campinas May/Aug. 2020 Epub Sep 16, 2020.

BORGES, W. F. Tecnologia assistiva e práticas de letramento no atendimento educacional especializado. 2015. $205 \mathrm{f}$. Dissertação (Mestrado em Educação) Universidade Federal de Goiás, Catalão, 2015.
Mesmo que exista um descompasso com a realidade existente nas escolas, principalmente as públicas, e a sociedade de modo geral, pode confirmar que tudo isso pode ser reformulado pautado na composição de premissas que contam com dedicação, esforço e criatividade, é visto que muitos alunos possuem aparelhos tecnológicos em suas próprias residências, mas poucos são aqueles que usufruem desses recursos para seu próprio aprendizado.

Dessa maneira o professor tem o papel de fazer com que estreite essa ligação de ambos e permita com que se aplique uma nova realidade, não só mediada pela metodologia, mas o engajamento, direcionamento e o afloramento de ideias inovadoras ao ensino que aproxime ainda mais o aluno ao meio tecnológico e possibilite o mesmo desvendar o verdadeiro valor da tecnologia em sua vida.

COSSON, Rildo. Literatura infantil em uma sociedade pós-literária: a dupla morfologia de um sistema cultural em movimento. Pro-Posições vol.27 no.2 Campinas May./Aug. 2016.

FRANCO, Raquel Aparecida Soares Reis; CASTANHEIRA, Maria Lúcia. Práticas de Letramento Acadêmico no Facebook. Ilha Desterro vol.69 no.3 Florianópolis Sept./Dec. 2016.

KIRCHOF, Edgar Roberto. Como ler os textos literários na era da cultura digital? Estud. Lit. Bras. Contemp. no.47 Brasília Jan./June 2016. 
LA BANCA, O. Rebecca; NASCIMENTO, Castanheira Lucila. Posicionando a criança no centro do seu cuidado: reflexões sobre 0 desenvolvimento cognitivo e o letramento em saúde infantil. Rev. esc. enferm. USP vol.53 São Paulo 2019 Epub Dec 02, 2019.

MACHADO, Souza Tatiane; CAPRISTANO, Carneiro Cristiane. Rasuras ligadas à segmentação de palavras na aquisição da escrita. Educ. rev. vol.32 no.1 Belo Horizonte Jan./Mar. 2016.

MEDEIROS, Zulmira. Gêneros, multimodalidades e letramentos. Rev. bras. linguist. apl. vol.14 no.3 Belo Horizonte July/Sept. 2014.

MOTTA, Lívia Maria Villela de Melo. Audiodescrição na escola: abrindo caminhos para leitura de mundo. Campinas, SP: Pontes Editores, 2016.

MIYAZAKI, Ana Rita de Souza. O Uso da Tecnologia para Alfabetizar e Letrar no
Século XXl. Revista Científica Multidisciplinar Núcleo do Conhecimento. Edição 04. Ano 02, Vol. 01. pp 219-230, Julho de 2017. ISSN:2448-0959.

NEVES, F. A. Vanessa; CASTANHEIRA, L. Maria; GOUVÊA, S. C. Maria. O letramento e o brincar em processos de socialização na educação infantil brincadeiras diferentes. Rev. Bras. Educ. vol.20 no.60 Rio de Janeiro Jan./Mar. 2015.

PRIMMA Z, Daniele. O uso da tecnologia na alfabetização de crianças. Porto Alegre: UF RS, 2015.

QUAST, Karin. Gamificação, ensino de línguas estrangeiras e formação de professores. Rev. bras. linguist. apl. vol.20 no.4 Belo Horizonte Sept./Dec. 2020 Epub Nov 18, 2020.

WAJSKOP, Gisela. Linguagem Oral e Brincadeira Letrada nas Creches. Educ. Real. vol.42 no.4 Porto Alegre Oct./Dec. 2017 Epub Mar 27, 2017. 